\title{
Insulin Therapy in Adults with Type 1 Diabetes Mellitus: a Narrative Review
}

\author{
Andrej Janež · Cristian Guja • Asimina Mitrakou • Nebojsa Lalic • \\ Tsvetalina Tankova · Leszek Czupryniak · Adam G. Tabák • \\ Martin Prazny $\cdot$ Emil Martinka $\cdot$ Lea Smircic-Duvnjak
}

Received: October 21, 2019 / Published online: January 4, 2020

(C) The Author(s) 2020

\section{ABSTRACT}

Here, we review insulin management options and strategies in nonpregnant adult patients with type 1 diabetes mellitus (T1DM). Most patients with T1DM should follow a regimen of multiple daily injections of basal/bolus insulin, but those not meeting individual glycemic targets or those with frequent or severe hypoglycemia or pronounced dawn phenomenon

Enhanced Digital Features To view enhanced digital features for this article go to https://doi.org/10.6084/ m9.figshare.11310668.

\section{A. Janež $(\bowtie)$}

Department of Endocrinology, Diabetes and Metabolic Diseases, University Medical Center Ljubljana, Zaloska 7, 1000 Ljubljana, Slovenia e-mail: Andrej.janez@kclj.si

\section{Guja}

Diabetes, Nutrition and Metabolic Diseases, "Carol Davila" University of Medicine and Pharmacy, Dionisie Lupu Street No. 37, 020021 Bucharest, Romania

\section{A. Mitrakou}

Department of Clinical Therapeutics, National and Kapodistrian University of Athens Medical School, Athens, Greece

N. Lalic

Faculty of Medicine of the University of Belgrade, Clinic for Endocrinology, Diabetes and Metabolic Diseases, Clinical Center of Serbia, Dr Subotica 13, 11000 Belgrade, Serbia should consider continuous subcutaneous insulin infusion. The latter treatment modality could also be an alternative based on patient preferences and availability of reimbursement. Continuous glucose monitoring may improve glycemic control irrespective of treatment regimen. A glycemic target of glycated hemoglobin $<7 \% \quad(53 \mathrm{mmol} / \mathrm{mol})$ is appropriate for most nonpregnant adults. Basal insulin analogues with a reduced peak profile and an extended duration of action with lower intraindividual variability relative to neutral protamine Hagedorn insulin are preferred. The clinical advantages of basal analogues compared

T. Tankova

Clinical Center of Endocrinology, Medical University of Sofia, 2, Zdrave Str, 1431 Sofia, Bulgaria

L. Czupryniak

Department of Diabetology and Internal Medicine, Medical University of Warsaw, Banacha 1a, 02-097 Warsaw, Poland

\section{A. G. Tabák}

1st Department of Medicine, Semmelweis University Faculty of Medicine, 2/a Korányi S. Str, 1083 Budapest, Hungary

\section{Prazny}

3rd Department of Internal Medicine, 1st Faculty of Medicine, Charles University in Prague, Prague, Czech Republic 
with older basal insulins include reduced injection burden, better efficacy, lower risk of hypoglycemic episodes (especially nocturnal), and reduced weight gain. For prandial glycemic control, any rapid-acting prandial analogue (aspart, glulisine, lispro) is preferred over regular human insulin. Faster-acting insulin aspart is a relatively new option with the advantage of better postprandial glucose coverage. Frequent blood glucose measurements along with patient education on insulin dosing based on carbohydrate counting, premeal blood glucose, and anticipated physical activity is paramount, as is education on the management of blood glucose under different circumstances.

Plain Language Summary: Plain language summary is available for this article.

Keywords: Continuous subcutaneous insulin infusion; Glycemic control; Insulin analogue; Insulin therapy; Multiple daily injections; Type 1 diabetes mellitus

\section{Key Summary Points}

Most adults with type 1 diabetes mellitus should be treated with multiple daily injections (1-2 injections of basal insulin and $\geq 3$ injections of prandial insulin per day).

Basal insulin analogues exhibit better efficacy compared with human neutral protamine Hagedorn insulin.

Second-generation basal insulin analogues show similar glycemic control as firstgeneration basal insulin analogues, but are associated with a lower risk of hypoglycemia and glycemic variability.

\section{E. Martinka}

Department of Diabetology, National Institute for Endocrinology and Diabetology, Kollarova 2/283, 03491 Lubochna, Slovakia

L. Smircic-Duvnjak

Vuk Vrhovac University Clinic-UH Merkur, School of Medicine, University of Zagreb, Dugi dol 4A, Zagreb, Croatia
Rapid-acting prandial insulin analogues have equivalent or better efficacy and lower hypoglycemia risk than regular human insulin.

\section{PLAIN LANGUAGE SUMMARY}

Type 1 diabetes mellitus (T1DM) is a condition in which the body can no longer produce sufficient amounts of its own insulin. As a result, blood sugar (glucose) levels increase and in the absence of supplemental insulin, diabetic coma and death will eventually occur. Moreover, if blood glucose levels are not properly regulated and are not corrected over time, heart disease, kidney disease, blindness, and nerve damage ensue. In order to meet the standard treatment target (glycated hemoglobin levels $<7 \%$ ), patients with T1DM require insulin supplementation, which is given as injections at set times of the day (basal) and at mealtimes (bolus or prandial). Patients may use a pump that provides a continuous supply of insulin if they do not meet treatment targets or if they have frequent or severe hypoglycemia, a condition which occurs when blood glucose is very low that may lead to anxiety, fatigue, confusion, seizures, and/or loss of consciousness. Basal insulin analogues are preferred over human insulin (neutral protamine Hagedorn). For mealtime insulin, any of the rapid-acting prandial insulin analogues are preferred over regular human insulin. For optimal management of T1DM, patients need to be educated on how to match prandial insulin dose to carbohydrate intake, premeal blood glucose, and anticipated physical activity as well as on how to measure their blood glucose and manage insulin dosing under various circumstances.

\section{INTRODUCTION}

Type 1 diabetes mellitus (T1DM) is a result of the destruction of insulin-producing pancreatic beta cells, leading to insulin deficiency $[1,2]$. The 
destruction of beta cells is usually the result of an autoimmune process, but in rare cases the cause might be unknown. T1DM was originally believed to develop mainly during childhood or adolescence [1], but it is now known that it can develop over the whole life span, even in individuals aged $>80$ years $[3,4]$. Most patients with T1DM are adults, partly because children diagnosed with T1DM will survive to adulthood but also because of new cases diagnosed in adults [5]. The identification of T1DM may be challenging, and T1DM may be misdiagnosed as type 2 diabetes mellitus (T2DM) in adults aged $>30$ year $[1,3]$. Latent autoimmune diabetes in adults, a form of T1DM that involves a slowly progressing immune-mediated loss of beta cells, may comprise $5-15 \%$ of T2DM cases $[2,5]$. Proper identification of T1DM is extremely important because these patients need to receive immediate insulin therapy and reach optimal glycemic control to prevent the onset of diabetic ketoacidosis, which is associated with an increased risk of death, and to delay microvascular and macrovascular complications [6-8].

Patients with T1DM require lifelong insulin replacement therapy from the time of diagnosis. Many insulin options for T1DM treatment are currently available, including human insulins and insulin analogues. In this review, we focus on insulin management options and strategies in nonpregnant adult patients with T1DM. When appropriate, we present the level of evidence associated with the treatment option/ strategy, with level A indicating clear evidence based on randomized, controlled, adequately powered trials; level B indicating supportive evidence based on well-conducted cohort or case-control studies; and level $\mathrm{C}$ indicating supportive evidence based on poorly controlled or uncontrolled studies.

This article is based on previously conducted studies and does not contain any studies with human participants or animals performed by any of the authors.

\section{CLINICAL EVALUATION}

The most recent guidelines for the diagnosis of T1DM are similar to those for T2DM (Table 1)
$[2,8,9]$. The American Diabetes Association (ADA) and the UK National Institute for Health and Care Excellence (NICE) guidelines recommend against routine testing of C-peptide or autoantibodies for diagnostic purposes [8, 9], but these could be used for clinically questionable cases. On the basis of the natural history of T1DM, three stages of T1DM development were proposed: stages 1 and 2 are both presymptomatic with detectable beta cell autoimmunity, with stage 2 additionally including dysglycemia (impaired fasting glucose or impaired glucose tolerance), and stage 3 is symptomatic with new-onset hyperglycemia $[8,10]$. Although preventing or delaying the development of T1DM is not yet a clinical option-thus screening for presymptomatic disease is not recommended in routine practice-identification of a high-risk group before the onset of hyperglycemia is possible based on the presence of multiple autoantibodies and dysglycemia.

\section{Glycemic Targets}

The large-scale prospective Diabetes Control and Complications Trial conclusively showed that intensive glycemic control with a basal-bolus insulin treatment regimen (reaching glycated hemoglobin [HbA1c] levels of approx. 7\%) is associated with reduced microvascular risk with respect to retinopathy, neuropathy, and diabetic kidney disease [7] and reduced long-term cardiovascular risk compared with conventional glycemic control with fixed dosing insulin regimens (reaching HbA1c levels of approx. 9\%) [6]. These results form the basis of current guideline recommendations. In general, evidence-based glycemic target recommendations by the ADA, Diabetes Canada, and NICE for adults with T1DM are all in agreement (Table 2). All recommend an HbA1c goal of $<7 \%(53 \mathrm{mmol} / \mathrm{mol}$; level A) for most nonpregnant adults, $<8 \% \quad(64 \mathrm{mmol} / \mathrm{mol})$ for patients with a history of severe hypoglycemia or severe comorbidities (level B), and $<6.5 \%$ (48 mmol/mol) if this goal is achievable without the risk of significant hypoglycemia or other adverse events (level C) [8]. Similarly, Diabetes 
Table 1 Diagnostic criteria for type 1 diabetes mellitus in adults recommended by the American Diabetes Association

\begin{tabular}{|c|c|}
\hline Diagnostics & Diagnostic criteria [8] \\
\hline tests & $\begin{array}{l}\text { - FPG } \geq 126 \mathrm{mg} / \mathrm{dL}(7.0 \mathrm{mmol} / \mathrm{L}) \text {, with no caloric intake for at least } 8 \mathrm{~h}^{\mathrm{a}} \\
\text { or } \\
\text { - } 2 \text {-h PG } \geq 200 \mathrm{mg} / \mathrm{dL}(11.1 \mathrm{mmol} / \mathrm{L}) \text { during OGTT, using a glucose load with the equivalent of } \\
75 \mathrm{~g} \text { of anhydrous glucose dissolved in water }{ }^{\mathrm{a}} \\
\text { or } \\
\text { - HbAlc } \geq 6.5 \%(48 \mathrm{mmol} / \mathrm{mol}) \text { performed using an NGSP-certified method standardized to the } \\
\text { DCCT assay } \\
\text { or } \\
\text { Random PG } \geq 200 \mathrm{mg} / \mathrm{dL}(11.1 \mathrm{mmol} / \mathrm{L}) \text { in patients with classic symptoms of hyperglycemia or } \\
\text { hyperglycemic crisis }\end{array}$ \\
\hline $\begin{array}{l}\text { Other diagnostic } \\
\text { criteria }\end{array}$ & $\begin{array}{l}\text { - Multiple autoantibodies (islet cell, GAD65, ZnT8, IA-2, anti-insulin) } \\
\text { - Undetectable or low C-peptide } \\
\text { - Family history/co-existence of other autoimmune diseases }\end{array}$ \\
\hline Clinical symptoms & $\begin{array}{l}\text { - Hyperglycemia } \\
\text { - Polyuria/polydipsia } \\
\text { - Unexplained weight loss } \\
\text { - Diabetic ketoacidosis }\end{array}$ \\
\hline Pathophysiology & - Beta cell destruction (occasionally dysfunction of remnant beta cells) \\
\hline
\end{tabular}

DCCT Diabetes Control and Complications Trial, FPG fasting plasma glucose, GAD65 glutamic acid decarboxylase, $H b A 1 c$ glycated hemoglobin, $I A-2$ islet antigen-2, NGSP National Glycohemoglobin Standardization Program, OGTT oral glucose tolerance test, $P G$ plasma glucose, $Z n T 8$ zinc transporter 8

${ }^{a}$ Results should be confirmed by repeat testing in the absence of unequivocal hyperglycemia

Canada recommends a target HbA1c of $\leq 7 \%$ $(53 \mathrm{mmol} / \mathrm{mol})$ for most patients with T1DM [2]. NICE recommends a target HbA1c of $\leq 6.5 \%$ $(48 \mathrm{mmol} / \mathrm{mol})$ for most patients with T1DM but suggests considering a person's daily activities, aspirations, likelihood of complications, comorbidities, occupation, and history of hypoglycemia when setting individualized targets [9].

Glycemic goals should be reassessed and individualized over time according to various patient and disease factors, including risks associated with hypoglycemia and other adverse events, disease duration, life expectancy, comorbidities, vascular complications, patient preferences, and resources/support systems [8]. According to the ADA recommendations, to achieve an HbA1c $<7 \%(53 \mathrm{mmol} /$ mol), preprandial capillary plasma glucose should be $4.4-7.2 \mathrm{mmol} / \mathrm{L}(80-130 \mathrm{mg} / \mathrm{dL})$ and peak postprandial capillary plasma glucose should be $<10 \mathrm{mmol} / \mathrm{L}$ (180 mg/dL) [8]. Similar levels are recommended by Diabetes Canada [2] and NICE [9]. With the advent of continuous glucose monitoring (CGM) systems, the time in blood glucose concentration range of 3.9-10 mmol/L (70-180 mg/dL) might become an additional indicator of overall glycemic control, which emphasizes the importance of decreasing blood glucose variability in addition to mean glucose values, with time in 
Table 2 Glycemic targets for type 1 diabetes mellitus in adults recommended by the American Diabetes Association, Diabetes Canada, and National Institute for Health and Care Excellence

\begin{tabular}{|c|c|c|c|}
\hline $\begin{array}{l}\text { Glycemic } \\
\text { targets }\end{array}$ & $\begin{array}{l}\text { American Diabetes } \\
\text { Association }[8]\end{array}$ & Diabetes Canada [2] & $\begin{array}{l}\text { National Institute for Health } \\
\text { and Care Excellence (NICE) [9] }\end{array}$ \\
\hline HbAlc & $\begin{array}{l}<7 \%(53 \mathrm{mmol} / \mathrm{mol})^{\mathrm{a}} \\
<8 \%(64 \mathrm{mmol} / \mathrm{mol}) \text { for } \\
\text { patients with history of severe } \\
\text { hypoglycemia or comorbid } \text { diseases }^{\mathrm{a}} \\
<6.5 \%(48 \mathrm{mmol} / \mathrm{mol}) \text { for } \\
\text { selected patients (short } \\
\text { duration of diabetes, long life } \\
\text { expectancy, or no significant } \\
\text { cardiovascular disease) if it } \\
\text { can be achieved without } \\
\text { significant hypoglycemia or } \\
\text { adverse events }\end{array}$ & $\begin{array}{l}\text { 7.1-8.5\% (54-69 mmol/mol) for } \\
\text { patients who are functionally } \\
\text { dependent; have a history of } \\
\text { recurrent severe hypoglycemia, } \\
\text { hypoglycemia unawareness, or } \\
\text { limited life expectancy; or who } \\
\text { are frail, are elderly, or have } \\
\text { dementia }\end{array}$ & $\begin{array}{l}\leq 6.5 \%(48 \mathrm{mmol} / \mathrm{mol}) \text { but } \\
\text { consider a person's daily } \\
\text { activities, aspirations, likelihood } \\
\text { of complications, comorbidities, } \\
\text { occupation, and history of } \\
\text { hypoglycemia }\end{array}$ \\
\hline $\begin{array}{l}\text { FPG or } \\
\text { preprandial } \\
\text { PG }\end{array}$ & $\begin{array}{l}4.4-7.2 \mathrm{mmol} / \mathrm{L} \\
\quad(80-130 \mathrm{mg} / \mathrm{dL})\end{array}$ & $\begin{array}{l}4.0-7.0 \mathrm{mmol} / \mathrm{L} \\
\quad(72-126 \mathrm{mg} / \mathrm{dL})\end{array}$ & $\begin{array}{l}5.0-7.0 \mathrm{mmol} / \mathrm{L} \\
\quad(90-126 \mathrm{mg} / \mathrm{dL}) \text { on waking } \\
4.0-7.0 \mathrm{mmol} / \mathrm{L} \\
(72-126 \mathrm{mg} / \mathrm{dL}) \text { before meals } \\
\text { or at other times of day }\end{array}$ \\
\hline $\begin{array}{l}\text { Peak } \\
\text { postprandial } \\
\text { PG }^{\mathrm{b}}\end{array}$ & $<10 \mathrm{mmol} / \mathrm{L}(180 \mathrm{mg} / \mathrm{dL})$ & $\begin{array}{l}5.0-10.0 \mathrm{mmol} / \mathrm{L} \\
\quad(90-180 \mathrm{mg} / \mathrm{dL} ; 2 \mathrm{~h})\end{array}$ & $\begin{array}{l}5.0-9.0 \mathrm{mmol} / \mathrm{L} \\
\quad(90-162 \mathrm{mg} / \mathrm{dL} ;>90 \mathrm{~min})\end{array}$ \\
\hline
\end{tabular}

HbAlc Glycated hemoglobin

${ }^{2}$ Postprandial glucose measurements should be made $1-2 \mathrm{~h}$ after the beginning of the meal, generally peak levels in patients with diabetes

${ }^{\mathrm{b}}$ Goals should be individualized on the basis of disease duration, life expectancy, comorbidities, and individual patient considerations

hypoglycemia a safety marker of insulin treatment in persons with T1DM [11].

\section{Insulin Therapy}

Insulin replacement is necessary for all people with T1DM and involves multiple daily injections (MDI) of basal and prandial insulin or continuous subcutaneous insulin infusion (CSII; level A) [8]. A variety of insulins (basal and prandial) and modes of administration (syringe, pen, prefilled pen, and pump) are available. Achieving optimal glycemic control while avoiding hypoglycemia and other adverse effects (such as excessive weight gain and lipodystrophy) requires individualized insulin therapy supplemented by glucose monitoring (either intermittent self-monitoring of blood glucose with a glucose meter or CGM) and proper therapeutic education (carbohydrate counting and insulin dose adjustments according to carbohydrate intake, activity levels, and blood glucose values, and proper injection technique) [2, 8, 9]. Basal insulins, which include long-acting insulin analogues (first generation: detemir and glargine $100 \mathrm{U} / \mathrm{mL}$ 
Table 3 Pharmacokinetic and pharmacodynamic properties of insulins

\begin{tabular}{|c|c|c|c|c|}
\hline Insulin type & Onset & Peak & $\begin{array}{l}\text { Duration } \\
\text { (h) }\end{array}$ & Molecular structure $^{a}$ \\
\hline \multicolumn{5}{|l|}{ Basal } \\
\hline \multicolumn{5}{|l|}{ Long acting } \\
\hline Detemir U100 & $1-2 \mathrm{~h}$ & None $^{b}$ & $<24$ & $\begin{array}{l}\text { Omission of B30 threonine; C14 fatty acid chain added to } \\
\text { B29 }\end{array}$ \\
\hline Gla-100 & $\sim 1 \mathrm{~h}$ & None $^{b}$ & 24 & $\begin{array}{l}\text { A21 asparagine replaced with glycine; } 2 \text { arginines added to } \\
\text { C-terminus of B chain }\end{array}$ \\
\hline Gla-300 & $6 \mathrm{~h}$ & None & $24-36$ & \\
\hline $\begin{array}{l}\text { Degludec U100 or } \\
\text { U200 }\end{array}$ & $\sim 1 \mathrm{~h}$ & None & Up to 42 & $\begin{array}{l}\text { Omission of B30 threonine; glutamic acid and C16 fatty } \\
\text { acid chain added to C-terminus of B chain }\end{array}$ \\
\hline \multicolumn{5}{|l|}{ Intermediate acting } \\
\hline NPH insulin U100 & $1-2 \mathrm{~h}$ & $4-14 h$ & $4-14 \mathrm{~h}$ & \\
\hline \multicolumn{5}{|l|}{ Bolus } \\
\hline $\begin{array}{l}\text { Rapid acting (lispro, } \\
\text { aspart, glulisine) }\end{array}$ & $5-15 \mathrm{~min}$ & $0.5-1.5 \mathrm{~h}$ & 3 to $<6$ & $\begin{array}{l}\text { Lispro: B28 proline replaced with lysine; B29 lysine replaced } \\
\text { with proline } \\
\text { Aspart: B28 proline replaced with aspartic acid } \\
\text { Glulisine: B3 asparagine replaced with lysine; B29 lysine } \\
\text { replaced with glutamic acid }\end{array}$ \\
\hline Faster-acting aspart & $2.5-4 \mathrm{~min}$ & $\sim 1 \mathrm{~h}$ & $3-5$ & Faster-acting aspart: B28 proline replaced with aspartic acid \\
\hline $\begin{array}{l}\text { Short acting (regular } \\
\text { human) }\end{array}$ & $30-60 \mathrm{~min}$ & $2-4 \mathrm{~h}$ & $6-12$ & \\
\hline
\end{tabular}

Pharmacokinetics data are from https://online.epocrates.com/tables/3201/Insulin-Comparisons. Molecular structure data are from [16]. There is significant inter- and intraindividual variability in pharmacokinetic and pharmacodynamic parameters; therefore, the time periods listed should be used as guidelines only Gla-100 Glargine $100 \mathrm{U} / \mathrm{mL}$, Gla-300 glargine $300 \mathrm{U} / \mathrm{mL}, \mathrm{NPH}$ neutral protamine Hagedorn

${ }^{a}$ Relative to NPH for basal insulins or relative to regular human insulin for bolus insulins

${ }^{\mathrm{b}}$ Can produce a peak effect in some persons, especially at higher doses

[Gla-100]; second generation: glargine 300 $\mathrm{U} / \mathrm{mL}$ [Gla-300] and degludec) or human intermediate-acting insulin (neutral protamine Hagedorn [NPH] insulin), are given 1-3 times a day according to their pharmacokinetic (PK) properties to control glucose levels in the fasting state and between meals (Table 3). Prandial insulins include rapid-acting insulin analogues (lispro, aspart, glulisine, and fast-acting aspart) or short-acting (regular human) insulin and are given before each meal, and at each time a correction of a high blood glucose value is required. Typically, prandial insulins are injected three times daily before main meals and are injected more often if $>3$ meals per day are consumed or correction boluses are required. Premixed insulins (either human or analogue insulins) are available but are not appropriate for patients with T1DM because the independent adjustment of basal and prandial insulin doses is not possible [2,9]. Rapid-acting inhaled insulin is available for use within a limited dose 
range, but large trials are needed for confirmation of efficacy. Furthermore, inhaled insulin is contraindicated in patients with chronic lung disease, is not recommended for those who smoke, costs at least twice that of other rapidacting insulins [8], and may require additional dosing after meals $[12,13]$.

Basal-bolus insulin regimens that mimic physiologic insulin secretion (usually MDI or, less frequently, CSII) should be initiated from the time of diagnosis of T1DM. The starting total daily insulin dose is typically weight based, ranging from 0.4 to 1.0 units per kilogram body weight, as recommended by various guidelines $[2,8,9]$. However, in some cases, particularly in newly diagnosed patients, the dose of insulin required may be less as a result of transient remission that may occur early after the initiation of insulin substitution. To prevent the risk of early hypoglycemia, a lower initial dose of between 0.3 and 0.4 units per kilogram body weight may be used. In contrast, a higher insulin dose of 0.7 units per kilogram body weight may be appropriate in the presence of ketones. In general, approximately half (40-60\%) of the total daily dose is given as basal insulin and the rest is divided into meal-related doses based on carbohydrate content. The exact insulin doses are reached by continuous titration; prandial doses are mainly conditioned on carbohydrate intake and to a lesser extent on protein and fat content, while basal insulin is dependent on body weight and insulin sensitivity [8].

To assess short-term glycemic control, it is recommended that most patients perform selfmonitoring of blood glucose (SMBG) at various times (before meals and snacks; at bedtime; occasionally overnight; $2 \mathrm{~h}$ postprandially to titrate dose of prandial insulin; prior to exercise; when low blood glucose is suspected; after treating low blood glucose until achieving normoglycemia; and before critical tasks) [2, 8]. CGM, along with intensive insulin regimens, can improve HbA1c in adults with T1DM who are not meeting glycemic targets (level A) [8]. CGM can also be useful for those with hypoglycemia unawareness and/or those with frequent hypoglycemic episodes (level B) [8]. For maximal benefit, CGM should be used daily or as frequently as possible to reach optimal glycemic effect (level A) [8].

\section{SEARCH METHODS}

Clinical trials comparing one or more types of insulin were found through multiple searches performed on PubMed (last search on 17 September 2019) for "insulin degludec," "insulin detemir," "insulin glargine," "insulin aspart," "insulin glulisine," and "insulin lispro," each combined with "AND type 1 diabetes," which yielded 2309 articles. No publication date limits were applied. After excluding nonEnglish language articles $(n=182)$, non-clinical trials articles $(n=1420)$, those articles on pediatric $(n=88)$, pregnant $(n=13)$, not exclusively T1DM $(n=26)$, or non-European ancestry $(n=16)$ populations, articles on discontinued or unavailable formulations $(n=23)$, or with no comparison of two formulations $(n=86)$ or efficacy $(n=37)$, studies in which $<100$ patients participated $(n=135)$, and duplicates, we retained 67 articles for consideration. Review articles and consensus papers were also identified through these PubMed searches before limits were applied.

\section{PHARMACOKINETICS, PHARMACODYNAMICS, CLINICAL EFFICACY, AND SAFETY WITH BASAL INSULIN ANALOGUES}

The basal insulin analogues have much improved efficacy and safety profiles and increased patient satisfaction over NPH insulin in patients with T1DM (Table 4). In general, use of long-acting basal insulin analogues results in fewer hypoglycemic episodes compared with the use of NPH insulin [2]. A meta-analysis of trials testing first-generation long-acting insulin analogues versus NPH insulin found a reduction in the risk of nocturnal hypoglycemic episodes and in the HbA1c level of patients using the former [14]. Another meta-analysis confirmed these results and also indicated less weight gain in patients on first-generation long-acting insulin analogues versus those on $\mathrm{NPH}$ insulin 







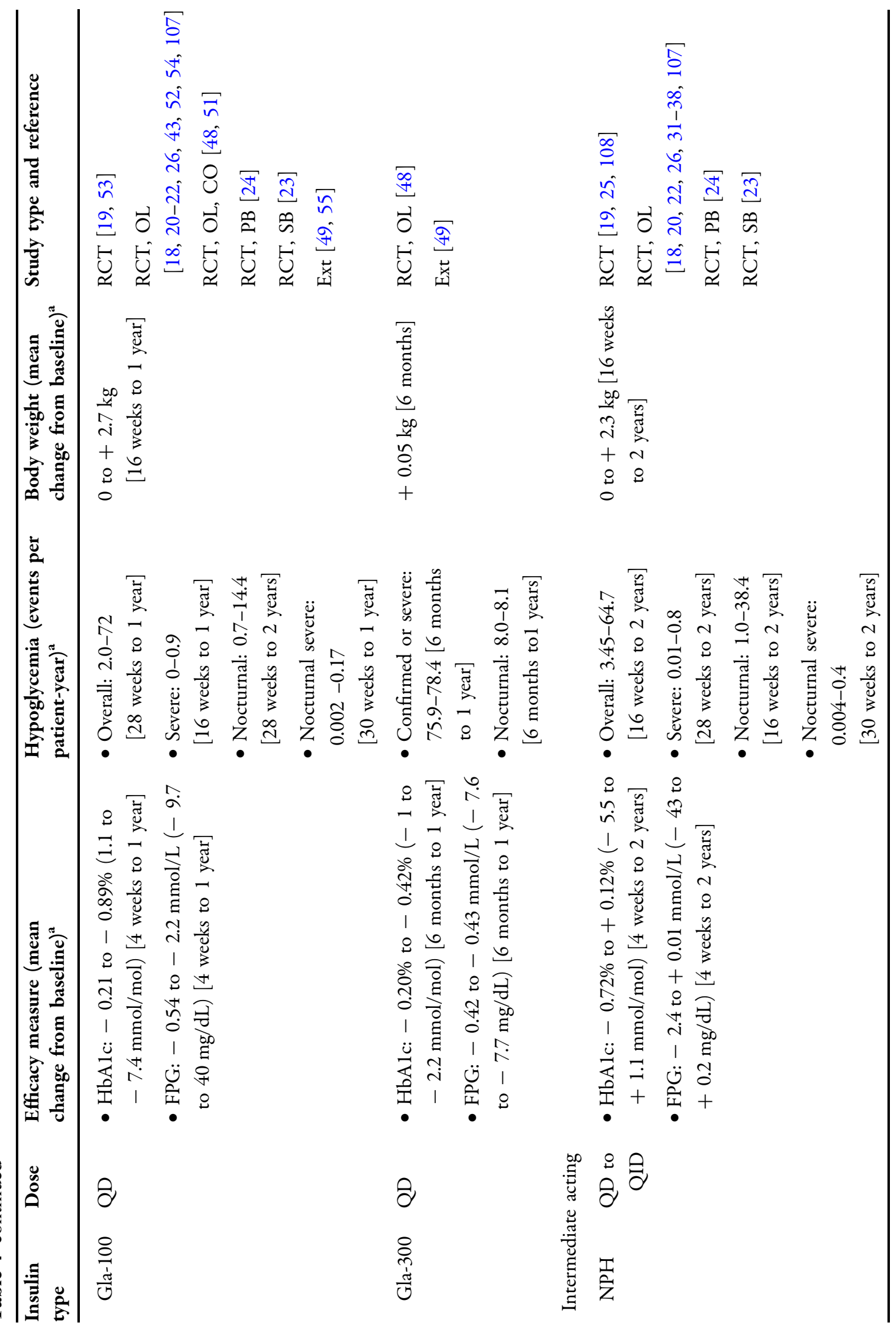




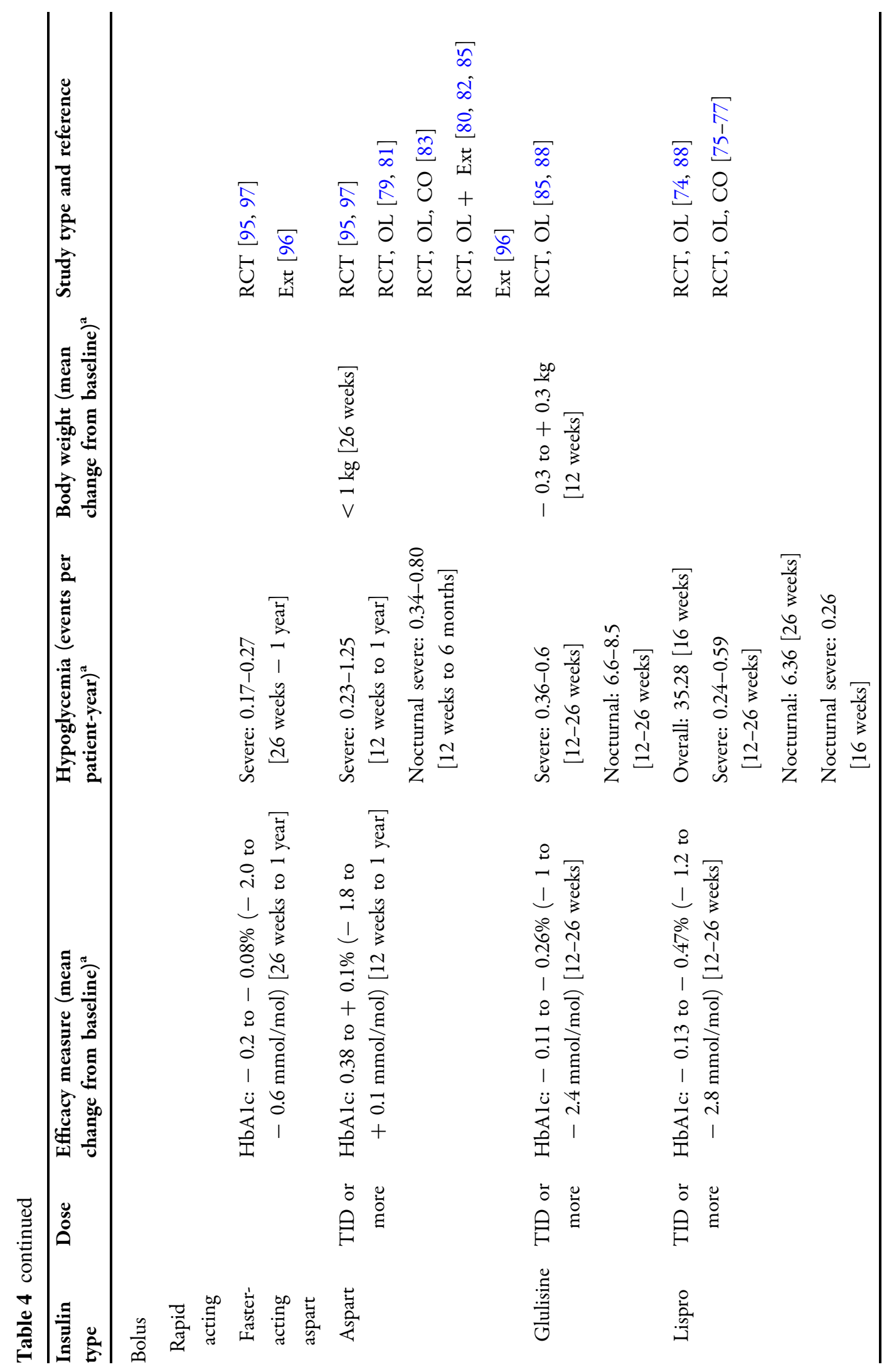






[15]. Comparative studies of these insulin analogues are discussed in the following sections, and Fig. 1 shows a proposed treatment algorithm for T1DM.

\section{Gla-100 Versus NPH Insulin}

Glargine is a long-acting insulin analogue which is a solution in the insulin vial that precipitates at physiologic $\mathrm{pH}$ in the subcutaneous tissue. These precipitates and the more stable hexamers result in a slower dissociation into dimers and monomers, leading to protracted absorption into the circulation [16]. Glargine has a reduced peak concentration/action profile compared to NPH insulin, and a lower interindividual variability than $\mathrm{NPH}$ insulin [17].

In general, Gla-100 once daily is comparable to [18-20] or better than [21-23] NPH insulin once or twice daily in maintaining glycemic control as measured by HbA1c. Similarly, decreases in fasting plasma/blood glucose are comparable [20] or significantly greater $[18,19,22-26]$ with Gla-100 than those with NPH insulin. Decreased weight gain in patients on Gla-100 compared with weight gain in those on NPH insulin has been observed [18]. Conflicting results have been found regarding hypoglycemia, with some studies reporting no difference between Gla-100 and NPH insulin $[18,20,26]$, but most reporting significantly fewer hypoglycemic events [22], including nocturnal events $[19,23,24]$, with Gla-100 than with NPH insulin. Several trials have observed significant improvement in patient satisfaction with Gla-100 versus NPH insulin regardless of baseline disease characteristics [27, 28].

\section{Insulin Detemir Versus NPH Insulin}

Detemir contains a fatty acid side chain that facilitates dihexamer formation and albumin binding, both of which slow its absorption at the injection site and into the circulation in the peripheral tissues [16]. Detemir has significantly less within-individual variability than $\mathrm{NPH}$ insulin in terms of PK and pharmacodynamic (PD) endpoints [29, 30]. Detemir has a flatter PD 


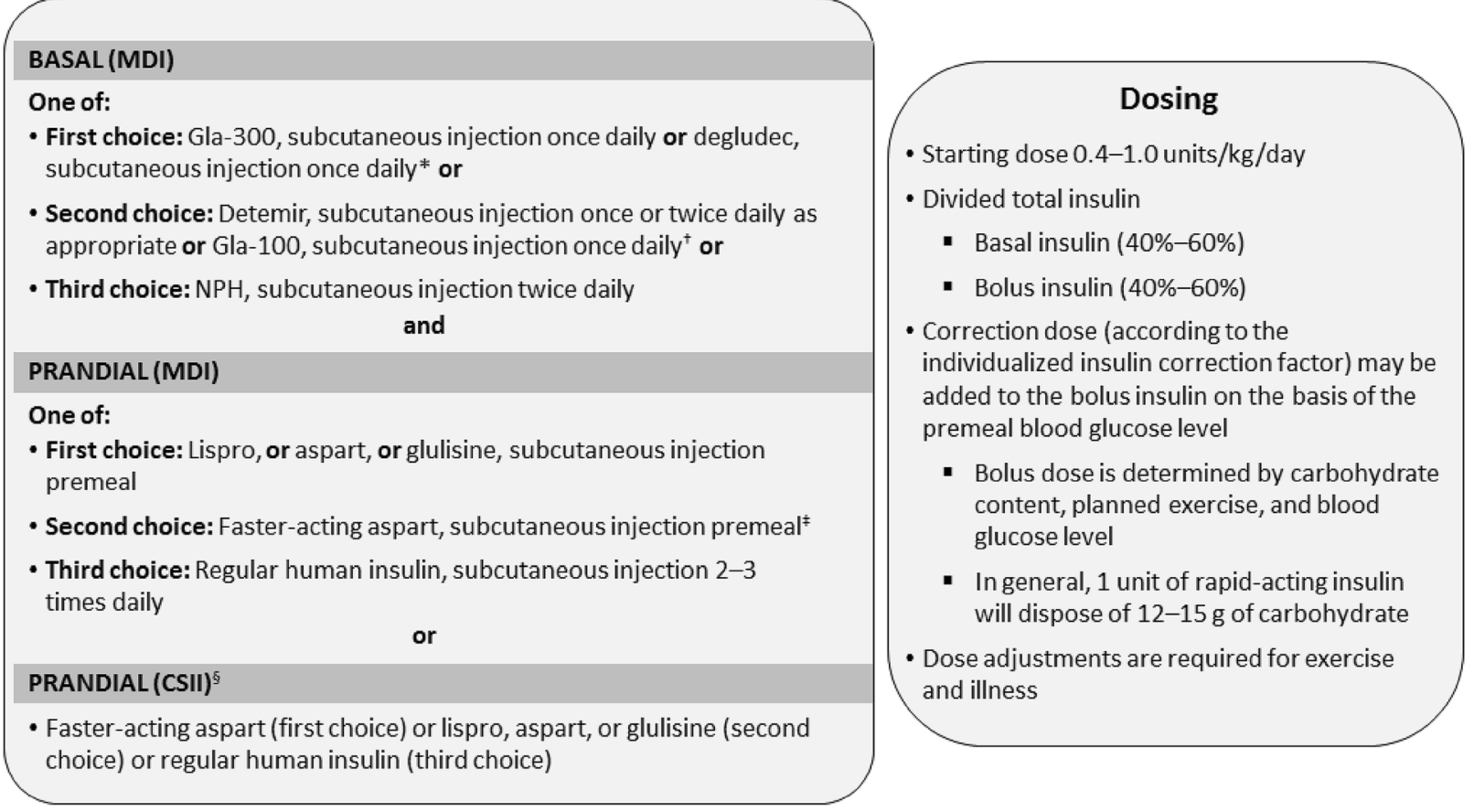

Fig. 1 A suggested treatment algorithm for type 1 diabetes mellitus for nonpregnant adults. Asterisk indicates that administration at any time (morning or evening) is appropriate for glargine $300 \mathrm{U} / \mathrm{mL}$ (Gla-300) or degludec. The single dagger indicates that evening administration is generally preferred for detemir and glargine $100 \mathrm{U} / \mathrm{mL}$ (Gla-100). The double dagger sign indicates a new agent not yet indicated for use with a pump. In some cases, it may be considered as first choice. The section sign

profile than NHP insulin and a longer duration of action [30].

In general, treatment with detemir or NPH insulin results in similar levels of HbA1c and/or fasting plasma glucose (FPG) [31-35], but detemir is associated with a lower risk of hypoglycemia [31, 33, 35-37], including nocturnal episodes [32-38]. A 2-year study found slightly lower HbA1c with detemir compared with NPH insulin ( 7.36 vs. $7.58 \%$ [ 57 vs. $59 \mathrm{mmol} / \mathrm{mol}])$, as well as lower FPG, mainly seen in the last 6 months of the study [37]. Weight loss or reduced weight gain was seen in patients on detemir versus those on NPH insulin; this is an important characteristic of detemir in persons with T1DM [31, 32, 34-38]. The day-to-day and within-individual variability in self-measured fasting blood glucose has been found to be significantly lower with detemir [34-36]. indicates possible use as first choice over multiple daily injections $(M D I)$ depending on patient preference if cost, reimbursement, and availability are not an issue after 3-6 months of training with MDI. Can be used as an alternative to MDI if glycemic targets are not met with MDI or if experiencing frequent hypoglycemia. CSII Continuous subcutaneous insulin infusion, NPH neutral protamine Hagedorn

The timing of detemir administration does not seem to affect clinical outcomes and may offer flexibility to accommodate individual patient needs. Similar glycemic control was seen with the administration of detemir either in the morning and before dinner or in the morning and at bedtime [39], and the risk of overall and nighttime hypoglycemia was found to be the same in either timing regimen [38]. Some reports indicate that the twice-daily administration of detemir is more common than once-daily dosing [40].

\section{Insulin Detemir Versus Gla-100}

The results of a clamp-based PK/PD study indicated that detemir and Gla-100 have similar PD effects based on glucose infusion rates during 
the first $12 \mathrm{~h}$ following administration but that rates with detemir (and thus its glucose-lowering effect) are lower between 12 and $24 \mathrm{~h}$, suggesting that a once-daily basal regimen for glargine and a twice-daily basal regimen for detemir might be the most appropriate approach [41]. The authors of a different clamp study reported that, under euglycemic clamp conditions, detemir was associated with a lower within-individual variability for glucose infusion rate and maximal concentration than Gla100 [29]. However, glargine was noninferior compared with detemir in terms of fasting blood glucose and other indices of glycemic variability in clinical practice settings, with a trend toward higher doses and number of injections with detemir than with glargine [42].

Similar reductions in HbA1c but significantly lower FPG were observed with glargine once daily versus detemir twice daily in a 26-week study. Of note, baseline HbA1c values were high (8.8 and $8.9 \%$ for glargine once daily and detemir twice daily, respectively). In this study, the risk of overall hypoglycemia was comparable with detemir and Gla-100, but the risks of severe and nocturnal hypoglycemia were lower with detemir [21]. However, a 1-year trial showed similar relative risks for total and nocturnal hypoglycemia with detemir and Gla-100 and that insulin detemir and Gla-100 have similar clinically significant improvements in glycemic control [43]. Taken together, these results (in agreement with a recent network meta-analysis on the subject) suggest no major, clinically relevant differences in the efficacy and safety of these basal insulin analogues [44].

\section{Gla-300 Versus Gla-100}

Glargine $100 \mathrm{U} / \mathrm{mL}$ is a second-generation basal insulin analogue that is threefold more concentrated than Gla-100; it also forms more compact precipitates at physiologic $\mathrm{pH}$ than Gla-100, which results in an even slower dissociation of monomers into the bloodstream [16]. Several PK/PD studies have found that Gla-300 has flatter (i.e., lower within-day variability or peak-to-trough differences) steady-state profiles and a longer duration of action than Gla-100 [45-47].

Overall, Gla-300 confers similar glycemic control as Gla-100, but with fewer nocturnal hypoglycemic events. The EDITION 4 trial showed similar glycemic control with Gla-300 and Gla-100 but that nocturnal or severe hypoglycemic events in the first 8 weeks of treatment were lower and there was less weight gain (difference of $-0.6 \mathrm{~kg}$ ) with Gla-300 [48]. The 6-month extension of the EDITION 4 trial found comparable glucose control in both treatment groups and similar rates of hypoglycemic events with Gla-100 and Gla-300 [49]. These findings are corroborated by a real-world, observational, retrospective study of patients in the UK which reported that there was no major change in the risk of severe hypoglycemia (1 vs. $2 \%$ ) with initiation of Gla-300 after 6 months despite a significant decrease in HbA1c of $0.4 \%$ $(4 \mathrm{mmol} / \mathrm{mol})$ and there was no significant weight gain [50].

\section{Insulin Degludec Versus Gla-100}

Degludec is a second-generation basal insulin analogue which forms multihexamer chains upon injection that slow the absorption of its monomers at the site of injection. In addition, its fatty acid side chain enables dihexamer formation and albumin binding [14]. In a number of studies, similar reductions in HbA1c [51-55] and weight gain $[51,53]$ were seen in patients on degludec versus those on Gla-100. However, similar [51, 52] or fewer overall hypoglycemic episodes [53] and fewer nocturnal hypoglycemic episodes [52-55] were reported with degludec compared with Gla-100.

\section{Insulin Degludec Versus Gla-300}

There is conflicting evidence regarding comparative PK and PD profiles of Gla-300 and degludec. In one study, Gla-300 had a more even steady-state PD/PK profile with $20 \%$ less within-day PD variability versus degludec U100, both at a clinically relevant dose of $0.4 \mathrm{U} / \mathrm{kg}$, although there was no significant difference at the $0.6 \mathrm{U} / \mathrm{kg}$ dose [56]. In contrast, another 
study found that degludec had a 37\% lower within-day variability and a fourfold lower dayto-day variability in terms of glucose-lowering effect compared with Gla-300 with both insulin analogues at a dose of $0.4 \mathrm{U} / \mathrm{kg}$ [57]. The conflicting observations may be explained by methodologic differences between studies, such as timing of doses, method of clamping, and definition of the time blocks for which the variability was calculated. There are currently no published head-to-head trials of Gla-300 and degludec in adults with T1DM.

\section{Degludec Versus Detemir}

A few head-to-head trials have compared degludec and detemir. Some trials reported that HbA1c decreased similarly with degludec and detemir at both 26 and 52 weeks [58-61], but the reduction in FPG was significantly greater with degludec at 26 and 52 weeks in one trial and its extension [58] but not at 52 weeks in another trial [59]. Also, significantly fewer nocturnal confirmed hypoglycemic events per patient-year were reported for degludec versus detemir, but the rates of overall confirmed hypoglycemic events per patient-year at 26 and 52 weeks were similar for both analogues [58-61].

\section{MULTIPLE DAILY INJECTIONS OF INSULIN ANALOGUES VERSUS CONTINUOUS SUBCUTANEOUS INSULIN INFUSION}

Continuous subcutaneous insulin infusion seems to be a more physiologic way to deliver insulin compared with MDI in that the delivery of the basal may be adjusted for different time intervals according to circadian variations of insulin sensitivity. This may improve glycemic control while lowering the risk of hypoglycemia $[2,62]$. The insulin infusion rate can also be temporarily changed (increased/decreased or stopped) to prevent extreme glucose swings or imminent hypoglycemia. Comparative randomized controlled trials of MDI versus CSII have involved small numbers of patients over a short time, but meta-analyses and registry data suggest a slight advantage for CSII with respect to HbA1c levels and severe hypoglycemia rates $[63,64]$. In addition, compared to MDI, CSII is associated with a better quality of life $[64,65]$ and greater patient satisfaction $[65,66]$. The addition of CGM to either MDI or CSII (sensoraugmented pump) appears to confer a greater reduction in HbA1c compared with MDI + selfmonitoring of blood glucose level, without increasing the time in hypoglycemia [2].

CSII and CGM technologies are evolving, and some modern sensor-augmented pump systems have been enhanced with a low-glucose suspend (LGS) or predictive LGS function that prevents insulin delivery when glucose levels fall below a set threshold in order to prevent hypoglycemia. In contrast, a closed-loop system uses a control algorithm to dispense insulin according to blood glucose levels in real time. Hybrid closed-loop system use (adjustment of basal infusion rate according to blood glucose level separately from prandial boluses) has been associated with significantly fewer hypoglycemic episodes and improved time in target glycemic range and treatment satisfaction than the usual pump therapy without $[67,68]$ or with LGS [69].

Physiologic basal-bolus insulin therapy (both MDI and CSII) remains the standard of care, although CSII technology is costly and not accessible to most patients with T1DM worldwide, especially in developing countries. It is recommended that patients start treatment with MDI and then try CSII if glycemic targets are not met with MDI or if they have pronounced dawn phenomenon, high glycemic variability, or problematic hypoglycemia (including nocturnal hypoglycemia, hypoglycemia unawareness, and hypoglycemia-associated autonomic failure) $[2,70]$. If cost, reimbursement, and availability are not an issue, depending on patient preferences, CSII could be a mode of delivery, but only after 3-6 months of training with MDI. Some patients may not be comfortable managing CSII, so experienced diabetes specialist(s) should assess those for whom it may be appropriate and have them followed by trained caregivers for proper usage. Specific educational programs are recommended for reducing the risk of hypo- and 
hyperglycemia during pump use [8]. Contraindications to CSII include patients' unwillingness to test their blood glucose multiple times per day, to count carbohydrates, to follow up with their healthcare provider, or to respond to pump alerts; history of non-adherence to SMBG/insulin injection protocols; history of serious psychological or psychiatric condition(s); and unrealistic expectations of pump therapy $[71,72]$.

\section{PRANDIAL INSULINS}

A short- or rapid-acting insulin is always needed at mealtimes to control glucose excursions after meals, except during the transient remission (honeymoon) period following insulin initiation [2] and in the early stages of latent autoimmune diabetes in adults. These insulins, given their relatively short duration of action, are also used as correction boluses to reduce occasional high blood glucose levels. Bolus insulins include the short-acting regular human insulin and rapid-acting analogues (lispro, aspart, glulisine, and faster insulin aspart).

The patient should determine the dose of prandial insulin by estimating the carbohydrate content of the meal using individualized insulin-to-carbohydrate ratios, the preprandial blood glucose level using an insulin correction factor, and the level of previous or planned physical activity [2]. The timing of bolus insulin administration may be an important determinant of postprandial glucose excursions [8]. Figure 1 provides an overview of a suggested treatment algorithm.

\section{Prandial Insulin Analogues Versus Regular Human Insulin}

Head-to-head trials have generally shown better or similar outcomes with rapid-acting insulin analogues compared with regular human insulin. A meta-analysis found small differences among lispro, aspart, and regular human insulin for HbA1c and a lower risk of severe or nocturnal hypoglycemia with the insulin analogues [73]. Glycemic control was similar or better in patients treated with lispro compared to regular human insulin [74-78]. Some trials found similar rates of overall [77], nocturnal, and/or severe nocturnal $[74,76]$ hypoglycemic events with lispro or regular human insulin, but others found significantly decreased nocturnal episodes with lispro versus regular human insulin [75]. Trials comparing aspart and regular human insulin (with basal NPH insulin) found small but significant decreases in HbA1c and significantly lower postprandial blood glucose levels with aspart at 6 [79, 80], 12 [80, 81], and 30 months [82]. Lower risks of nocturnal severe [83] or severe and nocturnal severe [79] hypoglycemic episodes were seen with aspart versus regular human insulin [79], but severe hypoglycemic episodes were comparable in others [81-83]. Another trial, also with basal NPH, found no significant differences in $\mathrm{HbA} 1 \mathrm{c}$ or severe hypoglycemic episodes between aspart and regular human insulin at 12 or 64 weeks [84]. In combination with basal insulin glargine, glulisine injected 0-15 min before meals (but not postmeal glulisine) showed significantly greater reductions in $\mathrm{HbA1c}$ than did the regular human insulin injected 30-45 min before meals, and severe hypoglycemic episodes were comparable [85].

In the few trials that have studied the use of prandial insulins administered via CSII, similar or better HbA1c values and rates of hypoglycemic episodes were reported for aspart and lispro compared to regular human insulin $[77,86]$. A recent meta-analysis of patients with T1DM receiving CSII showed that rapid-acting insulin analogues reduced postprandial glucose better than did regular human insulin, with a similar risk of hypoglycemia and a trend toward lower HbA1c [87].

\section{Comparisons of Prandial Insulin Analogues}

Overall, the rapid-acting prandial insulin analogues have similar efficacy. No differences were reported in HbA1c reduction and in rates of symptomatic hypoglycemia (overall, nocturnal, and severe) in 26-week sudy comparing glulisine and lispro [88]. Similarly, equivalent PK 
and PD effects were seen in another study with aspart and lispro [89]. Treatment adherence is generally better with the pen than with the syringe/vial modality [90]. Among the rapid-acting prandial insulin analogues used in CSII, somewhat better efficacy was seen for aspart than lispro and glulisine in one trial [87], and in another trial aspart seemed to have greater stability in the pump and lower rates of infusion set occlusions [91]. However, a third trial found no significant differences among glulisine, aspart, and lispro for HbA1c, severe hypoglycemia, or infusion set occlusions [92].

A newer formulation of aspart, referred to as faster-acting insulin aspart, contains the excipients nicotinamide and arginine; this new formulation shows a faster initial absorption and may show a more physiologic profile with a twofold faster onset and greater early glucoselowering effect compared with aspart [93, 94]. Dose-concentration and dose-response relationships and within-individual variability are similar between aspart and faster-acting aspart $[93,94]$. Both showed similar reductions in HbA1c rates and number of severe hypoglycemic episodes and had similar safety profiles [95], but significantly smaller postprandial plasma glucose increments were seen with faster-acting aspart than with aspart at 26 and 52 weeks [95-97].

\section{BIOSIMILAR INSULIN ANALOGUES}

Biosimilar insulins are now available, and their main advantage is reduced cost compared with the branded versions. The biosimilar Gla-100 LY2963016 was shown to provide glucose control and safety profiles similar to those of the original Gla-100 in patients with T1DM [98]. Similarly, a large trial of SAR342434, a biosimilar of lispro, showed noninferiority to lispro and similar changes in HbA1c, FPG, hypoglycemic events, and adverse events [99]. However, given the limited amount of evidence on the onset and duration of action, peak effect, efficacy, potency (dosing), and adverse events of biosimilars, a recent position statement from the International Diabetes Foundation Europe cautions on changing patients from their current insulin without good clinical reason or evidence of interchangeability and highlights the need for long-term studies on biosimilars [100]. In addition, country-specific regulations on switching insulins may limit the prescriptions of biosimilar insulins.

\section{FUTURE TRENDS OF INSULINS}

Research and development are in progress on insulins with improved properties, such as better mode of delivery or activation. Oral administration of basal insulin would avoid injections and may also deliver the insulin in a more physiologic manner through absorption through the portal vein [101]. Some studies have shown no significant difference orally and subcutaneously administered insulin in terms of PK, PD, and safety parameters, but larger and longer trials are still needed [102].

Another area of research has centered on "smart" or glucose-responsive insulin, which would help patients avoid hypoglycemic events [103]. This could be accomplished by surrounding the insulin molecules with a matrix that can sense blood glucose concentrations and release the insulin accordingly. In other cases, the insulin molecule itself is modified to allow activation under glucose-replete conditions. While some of these novel insulins have shown promise in preclinical studies, the T1DM community awaits their testing in large, randomized controlled clinical trials.

\section{DAWN PHENOMENON AND INSULIN: IMPLICATIONS ON DOSE TIMING}

Patients with T1DM in general experience a modest rise in blood glucose of approximately $0.8-1.4 \mathrm{mmol} / \mathrm{mol}$ (approx. $14-25 \mathrm{mg} / \mathrm{dL}$ ) in the morning hours (both before and after breakfast), an increase known as the dawn phenomenon [104]. In some patients, the degree of this increase could be much more pronounced. Nocturnal spikes of growth hormone [105] and/or cortisol [106], both with hyperglycemic effects, are the likely causes of this phenomenon, usually of 
higher magnitude in adolescents and young adults. CGM greatly assists in the diagnosis of dawn phenomenon [105]. Some of the strategies to counteract this effect include adjusting the dose, type, or timing (i.e., dinnertime to bedtime) of basal insulin, changing to an earlier injection of the morning bolus insulin, or using CSII for extra insulin delivery during the early morning hours, as needed. CSII delivery is the gold standard for patients with a pronounced dawn phenomenon [2].

\section{CONCLUSIONS}

There are many insulin treatment options and delivery methods for persons with T1DM, including new insulin formulations and hybrid closed-loop systems. A suggested treatment algorithm for T1DM is summarized in Fig. 1. Although CSII is recommended over MDI in adult patients with T1DM as it can improve glycemic control and the risk of hypoglycemia, due to cost and availability issues, the most used insulin regimen in the treatment of T1DM is MDI, especially in low-income countries. If glycemic targets are not achieved, or if there is high glycemic variability, frequent hypoglycemia, hypoglycemia unawareness, or pronounced dawn phenomenon, CSII is recommended. CGM is recommended for patients who can commit to its daily use regardless of whether they are receiving MDI or CSII. People with T1DM in general should use basal insulin analogues to reduce the risk of hypoglycemia and weight gain and because basal insulin analogues generally exhibit better efficacy than NPH insulin. Second-generation basal insulin analogues (Gla-300 and degludec) provide similar glycemic control and a lower risk of hypoglycemia (mainly nocturnal) and glycemic variability compared with first-generation basal insulin analogues (Gla-100 and detemir), and thus their use may be also recommended in patients with increased risk of hypoglycemia. Some cases require twice-daily dosing of the basal analogues, which is more frequently seen with detemir than with other basal insulin analogues.

All patients with T1DM require bolus insulins for prandial glycemic control. Patients should be educated on how to match prandial insulin dose to carbohydrate intake, premeal blood glucose, anticipated activity, and flexible insulin dosing. The rapid-acting prandial insulins show generally comparable efficacy with each other and equivalent or better efficacy and lower hypoglycemia risk than short-acting regular human insulin, with the faster-acting aspart offering additional benefits versus aspart.

\section{ACKNOWLEDGEMENTS}

Funding. Sanofi provided funding for the development of this article and the journal's Rapid Service Fee.

Medical Writing Assistance. Jennifer L. Giel, PhD, and Meri D. Pozo, PhD, on behalf of inScience Communications, Springer Healthcare (New York, NY, USA), on the basis of input from authors, wrote and edited the manuscript. This assistance was funded by Sanofi.

Authorship. All named authors meet the International Committee of Medical Journal Editors (ICMJE) criteria for authorship for this article, take responsibility for the integrity of the work as a whole, and have given their approval for this version to be published.

Authorship Contributions. The authors had full editorial control of the manuscript, contributed equally to its development, reviewed and edited various drafts, and provided their final approval of all content.

Disclosures. Andrej Janež has served as a consultant and is on Speakers Bureaus for Astra Zeneca, Boehringer Ingelheim, Eli Lilly, Merck Sharp \& Dohme (MSD), Novo Nordisk, and Sanofi. Cristian Guja has served as a consultant for Astra Zeneca, Boehringer Ingelheim, Eli Lilly, Novo Nordisk, and Sanofi; has received a research grant from UEFISCDI Romania; and is on Speakers Bureaus for Astra Zeneca, Boehringer Ingelheim, Eli Lilly, Merck KGaA, MSD, Novo Nordisk, and Sanofi. Asimina Mitrakou has served as a consultant for Astra Zeneca, 
Abbott, Bristol-Myers Squibb, and Medtronic; has received a research grant from Astra Zeneca and GlaxoSmithKline; and is on Speakers Bureaus for Boehringer Ingelheim and Novartis. Nebojsa Lalic has served as a lecturer at the Symposia of Novo Nordisk, Sanofi, Eli Lilly, Astra Zeneca, Boehringer Ingelheim, and Medtronic. Tsvetalina Tankova has served as a consultant for Astra Zeneca, Boehringer Ingelheim, MSD, and Sanofi and is on Speakers Bureaus for Astra Zeneca, Boehringer Ingelheim, Eli Lilly, MSD, Novo Nordisk, Sanofi, Servier, and Mylan. Leszek Czupryniak has served as a consultant for Abbott, Astra Zeneca, Boehringer Ingelheim, Eli Lilly, MSD, Novo Nordisk, Roche, and Sanofi and is on Speakers Bureaus for Astra Zeneca, Bioton, Boehringer Ingelheim, Eli Lilly, Gedeon Richter, Johnson \& Johnson, Merck Serono, MSD, Novo Nordisk, Sanofi, and Servier. Adam G. Tabák has served as a consultant for 77 Electronika, Eli Lilly, and Sanofi and is on Speakers Bureaus for Astra Zeneca, Berlin Chemie, Eli Lilly, Novo Nordisk, and Sanofi. Martin Prazny has served as consultant for Abbott, AstraZeneca, Boehringer Ingelheim, Dexcom, Eli Lilly, Medtronic, Novo Nordisk, Roche, Sanofi, and Takeda and is on Speakers Bureaus for Abbott, Boehringer Ingelheim, Dexcom, Eli Lilly, Medtronic, Novartis, Novo Nordisk, Roche, Sanofi, and Teva. Emil Martinka has served as a consultant for Abbott, AstraZeneca, Boehringer Ingelheim, Eli Lilly, Medtronic, Novo Nordisk, Roche, and Sanofi and is on Speakers Bureaus for Boehringer Ingelheim, Eli Lilly, Medtronic, Novo Nordisk, and Sanofi. Lea Smircic-Duvnjak has served as a consultant for Boehringer Ingelheim, Novo Nordisk, and Sanofi and is on Speakers Bureaus for Astra Zeneca, Boehringer Ingelheim, Eli Lilly, MSD, Novo Nordisk, Sandoz, Sanofi, and Takeda.

Compliance with Ethics Guidelines. This article is based on previously conducted studies and does not contain any studies with human participants or animals performed by any of the authors.

Open Access. This article is distributed under the terms of the Creative Commons Attribution-NonCommercial 4.0 International
License (http://creativecommons.org/licenses/ by-nc/4.0/), which permits any noncommercial use, distribution, and reproduction in any medium, provided you give appropriate credit to the original author(s) and the source, provide a link to the Creative Commons license, and indicate if changes were made.

\section{REFERENCES}

1. Atkinson M. The pathogenesis and natural history of type 1 diabetes. Cold Spring Harb Perspect Med. 2012;2(11):a007641. https://doi.org/10.1101/cshpe rspect.a007641.

2. Diabetes Canada. 2018 clinical practice guidelines for the prevention and management of diabetes in Canada. Can J Diabetes. 2018;42(Suppl 1):S1-325.

3. Thomas NJ, Jones SE, Weedon MN, Shields BM, Oram RA, Hattersley AT. Frequency and phenotype of type 1 diabetes in the first six decades of life: a cross-sectional, genetically stratified survival analysis from UK Biobank. Lancet Diabetes Endocrinol. 2018;6:122-9.

4. Thunander $\mathrm{M}$, Petersson $\mathrm{C}$, Jonzon $\mathrm{K}$, et al. Incidence of type 1 and type 2 diabetes in adults and children in Kronoberg, Sweden. Diabetes Res Clin Pract. 2008;82:247-55.

5. Skyler JS, Bakris GL, Bonifacio E, et al. Differentiation of diabetes by pathophysiology, natural history, and prognosis. Diabetes. 2017;66:241-55.

6. Diabetes Control and Complications Trial (DCCT)/ Epidemiology of Diabetes Interventions and Complications (EDIC) Study Research Group. Intensive diabetes treatment and cardiovascular outcomes in type 1 diabetes: the DCCT/EDIC study 30-year follow-up. Diabetes Care. 2016;39:686-93.

7. Nathan DM, Genuth S, Lachin J, et al. The effect of intensive treatment of diabetes on the development and progression of long-term complications in insulin-dependent diabetes mellitus. N Engl J Med. 1993;329:977-86.

8. American Diabetes Association. Standards of medical care in diabetes-2019. Diabetes Care. 2019;42: S1-193.

9. National Institute for Health and Care Excellence (NICE). Type 1 diabetes in adults: diagnosis and management London: National Institute for Health and Care Excellence (UK); 2015. https://www.nice. org.uk/guidance/ng17. Accessed 14 Nov 2018. 
10. Insel RA, Dunne JL, Atkinson MA, et al. Staging presymptomatic type 1 diabetes: a scientific statement of JDRF, the Endocrine Society, and the American Diabetes Association. Diabetes Care. 2015;38:1964-74.

11. Beck RW, Bergenstal RM, Riddlesworth TD, et al. Validation of time in range as an outcome measure for diabetes clinical trials. Diabetes Care. 2019;42: $400-5$.

12. Bode BW, McGill JB, Lorber DL, Gross JL, Chang PC, Bregman DB. Inhaled technosphere insulin compared with injected prandial insulin in type 1 diabetes: a randomized 24-week trial. Diabetes Care. 2015;38:2266-73.

13. Akturk HK, Snell-Bergeon JK, Rewers A, et al. Improved postprandial glucose with inhaled technosphere insulin compared with insulin aspart in patients with type 1 diabetes on multiple daily injections: the STAT study. Diabetes Technol Ther. 2018;20:639-47.

14. Laranjeira FO, de Andrade KRC, Figueiredo A, Silva EN, Pereira MG. Long-acting insulin analogues for type 1 diabetes: an overview of systematic reviews and meta-analysis of randomized controlled trials. PLOS ONE. 2018;13:e0194801.

15. Tricco AC, Ashoor HM, Antony J, et al. Safety, effectiveness, and cost effectiveness of long acting versus intermediate acting insulin for patients with type 1 diabetes: systematic review and network meta-analysis. BMJ. 2014;349:g5459.

16. Heise T, Mathieu C. Impact of the mode of protraction of basal insulin therapies on their pharmacokinetic and pharmacodynamic properties and resulting clinical outcomes. Diabetes Obes Metab. 2017;19:3-12.

17. Lepore M, Pampanelli S, Fanelli C, et al. Pharmacokinetics and pharmacodynamics of subcutaneous injection of long-acting human insulin analog glargine, NPH insulin, and ultralente human insulin and continuous subcutaneous infusion of insulin lispro. Diabetes. 2000;49:2142-8.

18. Raskin P, Klaff L, Bergenstal R, Halle JP, Donley D, Mecca T. A 16-week comparison of the novel insulin analog insulin glargine (HOE 901) and NPH human insulin used with insulin lispro in patients with type 1 diabetes. Diabetes Care. 2000;23:1666-71.

19. Ratner RE, Hirsch IB, Neifing JL, Garg SK, Mecca TE, Wilson CA. Less hypoglycemia with insulin glargine in intensive insulin therapy for type 1 diabetes. US Study Group of Insulin Glargine in Type 1 Diabetes. Diabetes Care. 2000;23:639-43.
20. Home PD, Rosskamp R, Forjanic-Klapproth J, Dressler A. A randomized multicentre trial of insulin glargine compared with NPH insulin in people with type 1 diabetes. Diabetes Metab Res Rev. 2005;21:545-53.

21. Pieber TR, Treichel HC, Hompesch B, et al. Comparison of insulin detemir and insulin glargine in subjects with type 1 diabetes using intensive insulin therapy. Diabet Med. 2007;24:635-42.

22. Porcellati F, Rossetti P, Pampanelli S, et al. Better long-term glycaemic control with the basal insulin glargine as compared with NPH in patients with type 1 diabetes mellitus given meal-time lispro insulin. Diabet Med. 2004;21:1213-20.

23. Fulcher GR, Gilbert RE, Yue DK. Glargine is superior to neutral protamine Hagedorn for improving glycated haemoglobin and fasting blood glucose levels during intensive insulin therapy. Intern Med J. 2005;35:536-42.

24. Pieber TR, Eugene-Jolchine I, Derobert E. Efficacy and safety of HOE 901 versus NPH insulin in patients with type 1 diabetes. The European Study Group of HOE 901 in type 1 diabetes. Diabetes Care. 2000;23:157-62.

25. Rosenstock J, Park G, Zimmerman J. Basal insulin glargine (HOE 901) versus NPH insulin in patients with type 1 diabetes on multiple daily insulin regimens. US Insulin Glargine (HOE 901) Type 1 Diabetes Investigator Group. Diabetes Care. 2000;23: 1137-42.

26. Bolli GB, Songini M, Trovati M, et al. Lower fasting blood glucose, glucose variability and nocturnal hypoglycaemia with glargine vs NPH basal insulin in subjects with type 1 diabetes. Nutr Metab Cardiovasc Dis. 2009;19:571-9.

27. Witthaus E, Stewart J, Bradley C. Treatment satisfaction and psychological well-being with insulin glargine compared with NPH in patients with type 1 diabetes. Diabet Med. 2001;18:619-25.

28. Polonsky W, Traylor L, Gao L, et al. Improved treatment satisfaction in patients with type 1 diabetes treated with insulin glargine $100 \mathrm{U} / \mathrm{mL}$ versus neutral protamine Hagedorn insulin: an exploration of key predictors from two randomized controlled trials. J Diabetes Complicat. 2017;31:562-8.

29. Heise T, Nosek L, Ronn BB, et al. Lower withinsubject variability of insulin detemir in comparison to NPH insulin and insulin glargine in people with type 1 diabetes. Diabetes. 2004;53:1614-20.

30. Plank J, Bodenlenz M, Sinner F, et al. A doubleblind, randomized, dose-response study investigating the pharmacodynamic and pharmacokinetic 
properties of the long-acting insulin analog detemir. Diabetes Care. 2005;28:1107-12.

31. Standl E, Lang H, Roberts A. The 12-month efficacy and safety of insulin detemir and NPH insulin in basal-bolus therapy for the treatment of type 1 diabetes. Diabetes Technol Ther. 2004;6:579-88.

32. De Leeuw I, Vague P, Selam JL, et al. Insulin detemir used in basal-bolus therapy in people with type 1 diabetes is associated with a lower risk of nocturnal hypoglycaemia and less weight gain over 12 months in comparison to NPH insulin. Diabetes Obes Metab. 2005;7:73-82.

33. Kolendorf K, Ross GP, Pavlic-Renar I, et al. Insulin detemir lowers the risk of hypoglycaemia and provides more consistent plasma glucose levels compared with NPH insulin in type 1 diabetes. Diabet Med. 2006;23:729-35.

34. Russell-Jones D, Simpson R, Hylleberg B, Draeger E, Bolinder J. Effects of QD insulin detemir or neutral protamine Hagedorn on blood glucose control in patients with type I diabetes mellitus using a basalbolus regimen. Clin Ther. 2004;26:724-36.

35. Vague P, Selam JL, Skeie $S$, et al. Insulin detemir is associated with more predictable glycemic control and reduced risk of hypoglycemia than NPH insulin in patients with type 1 diabetes on a basal-bolus regimen with premeal insulin aspart. Diabetes Care. 2003;26:590-6.

36. Hermansen K, Fontaine P, Kukolja KK, Peterkova V, Leth G, Gall MA. Insulin analogues (insulin detemir and insulin aspart) versus traditional human insulins (NPH insulin and regular human insulin) in basal-bolus therapy for patients with type 1 diabetes. Diabetologia. 2004;47:622-9.

37. Bartley PC, Bogoev M, Larsen J, Philotheou A. Longterm efficacy and safety of insulin detemir compared to neutral protamine Hagedorn insulin in patients with type 1 diabetes using a treat-to-target basal-bolus regimen with insulin aspart at meals: a 2-year, randomized, controlled trial. Diabet Med. 2008;25:442-9.

38. Home P, Bartley P, Russell-Jones D, et al. Insulin detemir offers improved glycemic control compared with NPH insulin in people with type 1 diabetes: a randomized clinical trial. Diabetes Care. 2004;27: 1081-7.

39. Pieber TR, Draeger E, Kristensen A, Grill V. Comparison of three multiple injection regimens for type 1 diabetes: morning plus dinner or bedtime administration of insulin detemir vs. morning plus bedtime NPH insulin. Diabet Med. 2005;22:850-7.
40. Hopkinson HE, Jacques RM, Gardner KJ, Amiel SA, Mansell P. Twice- rather than once-daily basal insulin is associated with better glycaemic control in type 1 diabetes mellitus 12 months after skillsbased structured education in insulin self-management. Diabet Med. 2015;32:1071-6.

41. Porcellati F, Rossetti P, Busciantella NR, et al. Comparison of pharmacokinetics and dynamics of the long-acting insulin analogs glargine and detemir at steady state in type 1 diabetes: a doubleblind, randomized, crossover study. Diabetes Care. 2007;30:2447-52.

42. Renard E, Dubois-Laforgue D, Guerci B. Non-inferiority of insulin glargine versus insulin detemir on blood glucose variability in type 1 diabetes patients: a multicenter, randomized, crossover study. Diabetes Technol Ther. 2011;13:1213-8.

43. Heller S, Koenen C, Bode B. Comparison of insulin detemir and insulin glargine in a basal-bolus regimen, with insulin aspart as the mealtime insulin, in patients with type 1 diabetes: a 52-week, multinational, randomized, open-label, parallel-group, treat-to-target noninferiority trial. Clin Ther. 2009;31:2086-97.

44. Dawoud D, O'Mahony R, Wonderling D, Cobb J, Higgins B, Amiel SA. Basal insulin regimens for adults with type 1 diabetes mellitus: a systematic review and network meta-analysis. Value Health. 2018;21:176-84.

45. Becker RH, Dahmen R, Bergmann K, Lehmann A, Jax T, Heise T. New insulin glargine 300 units mL-1 provides a more even activity profile and prolonged glycemic control at steady state compared with insulin glargine 100 units mL-1. Diabetes Care. 2015;38:637-43.

46. Steinstraesser A, Schmidt R, Bergmann K, Dahmen $\mathrm{R}$, Becker $\mathrm{RH}$. Investigational new insulin glargine $300 \mathrm{U} / \mathrm{ml}$ has the same metabolism as insulin glargine $100 \mathrm{U} / \mathrm{ml}$. Diabetes Obes Metab. 2014;16: 873-6.

47. Porcellati F, Lucidi P, Candeloro P, et al. Pharmacokinetics, pharmacodynamics, and modulation of hepatic glucose production with insulin glargine U300 and glargine U100 at steady state with individualized clinical doses in type 1 diabetes. Diabetes Care. 2019;42:85-92.

48. Home PD, Bergenstal RM, Bolli GB, et al. New insulin glargine 300 units $/ \mathrm{mL}$ versus glargine 100 units/mL in people with type 1 diabetes: a randomized, phase 3a, open-label clinical trial (EDITION 4). Diabetes Care. 2015;38:2217-25.

49. Home PD, Bergenstal RM, Bolli GB, et al. Glycaemic control and hypoglycaemia during 12 months of 
randomized treatment with insulin glargine 300 $\mathrm{U} / \mathrm{mL}$ versus glargine $100 \mathrm{U} / \mathrm{mL}$ in people with type 1 diabetes (edition 4). Diabetes Obes Metab. 2018;20:121-8.

50. Pang T, Bain SC, Black RNA, et al. A multicentre, $\mathrm{UK}$, retrospective, observational study to assess the effectiveness of insulin glargine 300 units/ml in treating people with type 1 diabetes mellitus in routine clinical practice (SPARTA). Diabet Med. 2019;36:110-9.

51. Heller S, Buse J, Fisher M, et al. Insulin degludec, an ultra-longacting basal insulin, versus insulin glargine in basal-bolus treatment with mealtime insulin aspart in type 1 diabetes (BEGIN Basal-Bolus Type 1): a phase 3, randomised, open-label, treat-to-target non-inferiority trial. Lancet. 2012;379:1489-97.

52. Mathieu C, Hollander P, Miranda-Palma B, et al. Efficacy and safety of insulin degludec in a flexible dosing regimen vs insulin glargine in patients with type 1 diabetes (BEGIN: flex T1): a 26-week randomized, treat-to-target trial with a 26-week extension. J Clin Endocrinol Metab. 2013;98:1154-62.

53. Lane W, Bailey TS, Gerety G, et al. Effect of insulin degludec vs insulin glargine U100 on hypoglycemia in patients with type 1 diabetes: the SWITCH 1 randomized clinical trial. JAMA. 2017;318:33-44.

54. Birkeland KI, Home PD, Wendisch U, et al. Insulin degludec in type 1 diabetes: a randomized controlled trial of a new-generation ultra-long-acting insulin compared with insulin glargine. Diabetes Care. 2011;34:661-5.

55. Bode BW, Buse JB, Fisher M, et al. Insulin degludec improves glycaemic control with lower nocturnal hypoglycaemia risk than insulin glargine in basalbolus treatment with mealtime insulin aspart in Type 1 diabetes (BEGIN $\left.{ }^{\circledR}\right)$ Basal-Bolus Type 1 ): 2 -year results of a randomized clinical trial. Diabet Med. 2013;30:1293-7.

56. Bailey TS, Pettus J, Roussel R, et al. Morning administration of $0.4 \mathrm{U} / \mathrm{kg} /$ day insulin glargine $300 \mathrm{U} / \mathrm{mL}$ provides less fluctuating 24-hour pharmacodynamics and more even pharmacokinetic profiles compared with insulin degludec $100 \mathrm{U} / \mathrm{mL}$ in type 1 diabetes. Diabetes Metab. 2018;44:15-21.

57. Heise T, Norskov M, Nosek L, Kaplan K, Famulla S, Haahr HL. Insulin degludec: lower day-to-day and within-day variability in pharmacodynamic response compared with insulin glargine $300 \mathrm{U} / \mathrm{mL}$ in type 1 diabetes. Diabetes Obes Metab. 2017;19: 1032-9.

58. Davies MJ, Gross JL, Ono Y, et al. Efficacy and safety of insulin degludec given as part of basal-bolus treatment with mealtime insulin aspart in type 1 diabetes: a 26-week randomized, open-label, treatto-target non-inferiority trial. Diabetes Obes Metab. 2014;16:922-30.

59. Hirsch IB, Franek E, Mersebach H, Bardtrum L, Hermansen K. Safety and efficacy of insulin degludec/insulin aspart with bolus mealtime insulin aspart compared with standard basal-bolus treatment in people with Type 1 diabetes: 1 -year results from a randomized clinical trial (BOOST ${ }^{\circledR} \mathrm{T} 1$ ). Diabet Med. 2017;34:167-73.

60. Davies M, Sasaki T, Gross JL, et al. Comparison of insulin degludec with insulin detemir in type 1 diabetes: a 1-year treat-to-target trial. Diabetes Obes Metab. 2016;18:96-9.

61. Hirsch IB, Bode B, Courreges JP, et al. Insulin degludec/insulin aspart administered once daily at any meal, with insulin aspart at other meals versus a standard basal-bolus regimen in patients with type 1 diabetes: a 26-week, phase 3, randomized, openlabel, treat-to-target trial. Diabetes Care. 2012;35: 2174-81.

62. International Hypoglycaemia Study Group. Minimizing hypoglycemia in diabetes. Diabetes Care. 2015;38:1583-91.

63. Yeh HC, Brown TT, Maruthur N, et al. Comparative effectiveness and safety of methods of insulin delivery and glucose monitoring for diabetes mellitus: a systematic review and meta-analysis. Ann Intern Med. 2012;157:336-47.

64. Misso ML, Egberts KJ, Page M, O'Connor D, Shaw J. Continuous subcutaneous insulin infusion (CSII) versus multiple insulin injections for type 1 diabetes mellitus. Cochrane Database Syst Rev. 2010;5(1): CD005103.

65. Nicolucci A, Maione A, Franciosi M, et al. Quality of life and treatment satisfaction in adults with type 1 diabetes: a comparison between continuous subcutaneous insulin infusion and multiple daily injections. Diabet Med. 2008;25:213-20.

66. REPOSE Study Group. Relative effectiveness of insulin pump treatment over multiple daily injections and structured education during flexible intensive insulin treatment for type 1 diabetes: cluster randomised trial (REPOSE). BMJ. 2017;356: j1285.

67. Bally L, Thabit H, Kojzar H, et al. Day-and-night glycaemic control with closed-loop insulin delivery versus conventional insulin pump therapy in freeliving adults with well controlled type 1 diabetes: an open-label, randomised, crossover study. Lancet Diabetes Endocrinol. 2017;5:261-70. 
68. Tauschmann M, Thabit H, Bally L, et al. Closed-loop insulin delivery in suboptimally controlled type 1 diabetes: a multicentre, 12-week randomised trial. Lancet. 2018;392:1321-9.

69. Sharifi A, De Bock MI, Jayawardene D, et al. Glycemia, treatment satisfaction, cognition, and sleep quality in adults and adolescents with type 1 diabetes when using a closed-loop system overnight versus sensor-augmented pump with low-glucose suspend function: a randomized crossover study. Diabetes Technol Ther. 2016;18:772-83.

70. National Institute for Health and Care Excellence (NICE). Type 1 diabetes in adults overview. https:// pathways.nice.org.uk/pathways/type-1-diabetes-inadults. Accessed 14 Nov 2018.

71. Saboo BD, Talaviya PA. Continuous subcutaneous insulin infusion: practical issues. Indian J Endocrinol Metab. 2012;16:S259-62.

72. Valla V. Continuous subcutaneous insulin infusion (CSII) pumps. In: Ahmad SI, editor. Diabetes: an old disease, a new insight. New York: Springer; 2011.

73. Singh SR, Ahmad F, Lal A, Yu C, Bai Z, Bennett H. Efficacy and safety of insulin analogues for the management of diabetes mellitus: a meta-analysis. CMAJ. 2009;180:385-97.

74. Brunetti P, Muggeo M, Cattin L, et al. Incidence of severe nocturnal hypoglycemia in patients with type 1 diabetes treated with insulin lispro or regular human insulin in addition to basal insulin glargine. Nutr Metab Cardiovasc Dis. 2010;20:519-26.

75. Heller SR, Amiel SA, Mansell P. Effect of the fastacting insulin analog lispro on the risk of nocturnal hypoglycemia during intensified insulin therapy. UK Lispro Study Group. Diabetes Care. 1999;22: 1607-11.

76. Holleman F, Schmitt H, Rottiers R, Rees A, Symanowski S, Anderson JH. Reduced frequency of severe hypoglycemia and coma in well-controlled IDDM patients treated with insulin lispro. The Benelux-UK Insulin Lispro Study Group. Diabetes Care. 1997;20:1827-32.

77. Renner R, Pfutzner A, Trautmann M, Harzer O, Sauter K, Landgraf R. Use of insulin lispro in continuous subcutaneous insulin infusion treatment. Results of a multicenter trial. German Humalog-CSII Study Group. Diabetes Care. 1999;22: 784-8.

78. Pfutzner A, Kustner E, Forst $\mathrm{T}$, et al. Intensive insulin therapy with insulin lispro in patients with type 1 diabetes reduces the frequency of hypoglycemic episodes. Exp Clin Endocrinol Diabetes. 1996;104:25-30.
79. Home PD, Lindholm A, Riis A. Insulin aspart vs. human insulin in the management of long-term blood glucose control in type 1 diabetes mellitus: a randomized controlled trial. Diabet Med. 2000;17: 762-70.

80. Raskin P, Guthrie RA, Leiter L, Riis A, Jovanovic L. Use of insulin aspart, a fast-acting insulin analog, as the mealtime insulin in the management of patients with type 1 diabetes. Diabetes Care. 2000;23:583-8.

81. Tamas G, Marre M, Astorga R, Dedov I, Jacobsen J, Lindholm A. Glycaemic control in type 1 diabetic patients using optimised insulin aspart or human insulin in a randomised multinational study. Diabetes Res Clin Pract. 2001;54:105-14.

82. Home PD, Hallgren P, Usadel KH, et al. Pre-meal insulin aspart compared with pre-meal soluble human insulin in type 1 diabetes. Diabetes Res Clin Pract. 2006;71:131-9.

83. Heller SR, Colagiuri S, Vaaler S, et al. Hypoglycaemia with insulin aspart: a double-blind, randomised, crossover trial in subjects with type 1 diabetes. Diabet Med. 2004;21:769-75.

84. DeVries JH, Lindholm A, Jacobsen JL, Heine RJ, Home PD. A randomized trial of insulin aspart with intensified basal NPH insulin supplementation in people with type 1 diabetes. Diabet Med. 2003;20: 312-8.

85. Garg SK, Rosenstock J, Ways K. Optimized basalbolus insulin regimens in type 1 diabetes: insulin glulisine versus regular human insulin in combination with basal insulin glargine. Endocr Pract. 2005;11:11-7.

86. Bode B, Weinstein R, Bell D, et al. Comparison of insulin aspart with buffered regular insulin and insulin lispro in continuous subcutaneous insulin infusion: a randomized study in type 1 diabetes. Diabetes Care. 2002;25:439-44.

87. Norgaard K, Sukumar N, Rafnsson SB, Saravanan P. Efficacy and safety of rapid-acting insulin analogs in special populations with type 1 diabetes or gestational diabetes: systematic review and meta-analysis. Diabetes Ther. 2018;9:891-917.

88. Dreyer M, Prager R, Robinson A, et al. Efficacy and safety of insulin glulisine in patients with type 1 diabetes. Horm Metab Res. 2005;37:702-7.

89. Plank J, Wutte A, Brunner G, et al. A direct comparison of insulin aspart and insulin lispro in patients with type 1 diabetes. Diabetes Care. 2002;25:2053-7. 
90. Racsa PN, Meah Y, Ellis JJ, Saverno KR. Comparative effectiveness of rapid-acting insulins in adults with diabetes. J Manag Care Spec Pharm. 2017;23:291-8.

91. Bode BW. Comparison of pharmacokinetic properties, physicochemical stability, and pump compatibility of 3 rapid-acting insulin analogues-aspart, lispro, and glulisine. Endocr Pract. 2011;17:271-80.

92. van Bon AC, Bode BW, Sert-Langeron C, DeVries JH, Charpentier G. Insulin glulisine compared to insulin aspart and to insulin lispro administered by continuous subcutaneous insulin infusion in patients with type 1 diabetes: a randomized controlled trial. Diabetes Technol Ther. 2011;13: 607-14.

93. Heise T, Hovelmann U, Brondsted L, Adrian CL, Nosek L, Haahr H. Faster-acting insulin aspart: earlier onset of appearance and greater early pharmacokinetic and pharmacodynamic effects than insulin aspart. Diabetes Obes Metab. 2015;17: 682-8.

94. Heise T, Stender-Petersen K, Hovelmann U, et al. Pharmacokinetic and pharmacodynamic properties of faster-acting insulin aspart versus insulin aspart across a clinically relevant dose range in subjects with type 1 diabetes mellitus. Clin Pharmacokinet. 2017;56:649-60.

95. Russell-Jones D, Bode BW, De Block C, et al. Fastacting insulin aspart improves glycemic control in basal-bolus treatment for type 1 diabetes: results of a 26-week multicenter, active-controlled, treat-totarget, randomized, parallel-group trial (onset 1). Diabetes Care. 2017;40:943-50.

96. Mathieu C, Bode BW, Franek E, et al. Efficacy and safety of fast-acting insulin aspart in comparison with insulin aspart in type 1 diabetes (onset 1): a 52-week, randomized, treat-to-target, phase III trial. Diabetes Obes Metab. 2018;20:1148-55.

97. Buse JB, Carlson AL, Komatsu M, et al. Fast-acting insulin aspart versus insulin aspart in the setting of insulin degludec-treated type 1 diabetes: efficacy and safety from a randomized double-blind trial. Diabetes Obes Metab. 2018;20:2885-93.

98. Blevins TC, Dahl D, Rosenstock J, et al. Efficacy and safety of LY2963016 insulin glargine compared with insulin glargine (Lantus ${ }^{\circledR}$ ) in patients with type 1 diabetes in a randomized controlled trial: the ELEMENT 1 study. Diabetes Obes Metab. 2015;17: 726-33.
99. Garg SK, Wernicke-Panten K, Rojeski M, Pierre S, Kirchhein Y, Jedynasty K. Efficacy and safety of biosimilar SAR342434 insulin lispro in adults with type 1 diabetes also using insulin glargine-SORELLA 1 study. Diabetes Technol Ther. 2017;19:516-26.

100. International Diabetes Foundation Europe. IDF Europe position on biosimilars in the treatment of people with diabetes; 2017. https:/www.idf.org/ our-network/regions-members/europe/europe-news/ 81-idf-europe-position-on-biosimilars-in-the-treat ment-of-people-with-diabetes.html. Accessed 5 Dec 2018.

101. Halberg IB, Lyby K, Wassermann K, Heise T, Zijlstra E, Plum-Morschel L. Efficacy and safety of oral basal insulin versus subcutaneous insulin glargine in type 2 diabetes: a randomised, double-blind, phase 2 trial. Lancet Diabetes Endocrinol. 2019;7:179-88.

102. Akbari V, Hendijani F, Feizi A, et al. Efficacy and safety of oral insulin compared to subcutaneous insulin: a systematic review and meta-analysis. J Endocrinol Invest. 2016;39:215-25.

103. Rege NK, Phillips NFB, Weiss MA. Development of glucose-responsive 'smart' insulin systems. Curr Opin Endocrinol Diabetes Obes. 2017;24:267-78.

104. Porcellati F, Lucidi P, Bolli GB, Fanelli CG. Thirty years of research on the dawn phenomenon: lessons to optimize blood glucose control in diabetes. Diabetes Care. 2013;36:3860-2.

105. O'Neal TB, Luther EE. Dawn phenomenon. Treasure Island: StatPearls; 2018.

106. Mallad A, Hinshaw L, Dalla Man C, et al. Nocturnal glucose metabolism in type 1 diabetes: a study comparing single versus dual tracer approaches. Diabetes Technol Ther. 2015;17:587-95.

107. Radman M, Jurisic D, Ljutic D, Jerkovic R, Kovacic $\mathrm{N}$, Hozo IS. Assessing glycemia in type 1 diabetic patients using a microdialysis system for continuous glucose monitoring. Ann Saudi Med. 2007;27: 166-70.

108. Rossetti P, Pampanelli S, Fanelli C, et al. Intensive replacement of basal insulin in patients with type 1 diabetes given rapid-acting insulin analog at mealtime: a 3-month comparison between administration of NPH insulin four times daily and glargine insulin at dinner or bedtime. Diabetes Care. 2003;26:1490-6. 